\title{
EVALUATION OF ANTIHYPERGLYCAEMIC EFFECT OF BUTEA MONOSPERMA LEAF EXTRACT ON ADRENALIN INDUCED AND HIGH GLUCOSE FEED ANIMAL MODEL
}

\author{
BISWARANJAN RAY ${ }^{1 *}$, SANTOSH KUMAR MAHAPATRA ${ }^{2}$, PRADIPTA KUMAR BEHERA ${ }^{1}$, ASHOK K PANIGRAHI ${ }^{3}$
}

${ }^{1}$ Department of PhD, Sambalpur University, Sambalpur, Odisha, India. ${ }^{2}$ Department of Pharmacy, Gayatri College of Pharmacy, Sambalpur, Odisha, India. ${ }^{3}$ Department of Pharmacology respectinely, Veer Surenrdra Sai Institute of Medical Sciences and Research, Sambalpur, Odisha, India. Email: crabiswa@gmail.com

Received: 22 July 2017, Revised and Accepted: 08 September 2017

ABSTRACT

Objective: As per the ethnopharmacological information has Butea monosperma been used to treat diabetes mellitus by the tribal people of tropical and subtropical areas. However, there is no much more scientific report available about the antidiabetic property of the leaves of the plant. Hence, the study was undertaken to evaluate the antidiabetic effect of ethanolic extract of $B$. monosperma on blood levels of adrenaline-induced and glucose feed diabetic rabbits.

Methods: The three different doses of the extracts $(100,200$, and $400 \mathrm{mg} / \mathrm{kg}$ ) were administered orally to an experimental animal. The animals were induced diabetics by adrenaline and high glucose diet. Blood glucose level was measured accordingly. For antidiabetic activity, photocolorimeter was used to monitoring the blood glucose level with crest kit box (GOP-POD method).

Results: The extracts showed considerable dose-dependent activity. However, the dose $400 \mathrm{mg} / \mathrm{kg}$ showed considerable lower of blood glucose level. $\mathrm{p}<0.01$ indicates the significance result. $8 \mathrm{hrs}$ reading $182.5 \pm 3.83$ for $400 \mathrm{mg}$ does is most effective for reducing blood sugar.

Conclusion: The study indicates that the ethanolic extract of $B$. monosperma leaves possesses antidiabetic properties which suggest the presence of biologically active components.

Keywords: Glucose, Adrenaline, Leaf extract, Hyperglycemia.

(C) 2017 The Authors. Published by Innovare Academic Sciences Pvt Ltd. This is an open access article under the CC BY license (http://creativecommons. org/licenses/by/4. 0/) DOI: http://dx.doi.org/10.22159/ajpcr.2017.v10i12.21501

\section{INTRODUCTION}

Diabetes mellitus is a chronic metabolic disorder characterized by high glucose concentration (hyperglycemias) due to impaired insulin secretion and or insulin resistance [1]. It is a metabolic disorder in which there is an inability to metabolize carbohydrate due to disturbances in insulin function and secretion. Diabetes is one of the oldest known diseases of the man whose devastating effect is increasing by the day and severity almost at an epidemic level. The identification parameter and treatment protocol are becoming complicated day-by-day. Diabetes is always associated with many other complications which may or may not be preexisting. The number of people suffering from the disease worldwide is increasing at an alarming rate with a projected 366 million peoples likely to be diabetic by the year 2030 as against 191 million estimated in 2000 (Wild et al., 2004). Developing countries are the most affected because of expansive and inadequate treatments (djr olo etd, 1998), coupled with the side effect associated with these drug [2].

Thus the search of a new drug with low cost, more potential and without adverse effect becomes inevitable. A great number of medicinal plants have been used in the treatment of diabetes in a different part of the world. Many herbal products are the mixture of different plant extract used for a therapeutic purpose which is based on its ethnobotanical information. Many times plant product are subjected to animal screening but sometimes these product used by following traditional information on the basis of traditional use. Evaluation of the antidiabetic potentials of these plants becomes necessary to provide scientific proof and justify their uses in ethnomedicine.

Butea monosperma is a species of Butea native to tropical and subtropical parts of the Indian Subcontinent and Southeast Asia, ranging across India, Bangladesh, Nepal, Pakistan, Sri Lanka, Myanmar, Thailand,
Laos, Cambodia, Vietnam, Malaysia, and western Indonesia 4,5. In this study, the different doses of leaf extracts were screened for antidiabetic study [3].

\section{METHODS}

Collection and leaf extract preparation

The plant leaves were collected based on local ethnobotanical information. The collected plant materials were subjected to authenticated identification using the standard of nomenclature and classification. The authentification has been certified by the Scientist, Botanical Survey of India (BSI), Kolkata.

The leaves were dried in the shade and powdered to get a coarse powder. About $800 \mathrm{~g}$ of dry, coarse powder was subjected to extraction with ethanol using Soxhlet apparatus. The residue of the extract obtained evaporated to dried mass and then the residue of the extract obtained was taken for the experiment $[4,5]$.

\section{Chemicals and reagent uses}

All chemicals and drugs were obtained commercially and were of analytical grade. All the reagent kits were obtained from crest India Ltd.

\section{Instrument used}

For antidiabetic activity photocolorimeter was used to monitoring the blood glucose level with crest kit box (GOP-POD method).

\section{Phytochemical screening}

The ethanolic extract of the leaves obtained was subjected to preliminary phytochemical screening to identify the chemical constituents. The methods of analysis employed were those described by Trease and Evans (1989) [6]. 
The presence of various constituent has been screened in a different chemical test using different chemical reagent. The finding of different chemical constituents is evidence for different pharmacological activity [7].

\section{Dose selection}

The three test drug dose and standard drug dose were selected by acute toxicity study $\left(\mathrm{LD}_{50}\right)$.

\section{Animals and induction of diabetes mellitus}

Healthy albino rabbits of either sex, inbred in the departmental animal house, weighing between 2 and $2.5 \mathrm{~kg}$, aged between 6 months and 1 year were used for this study. The animals were kept properly and maintain required condition suitable for experiment before and during experiment. Adrenaline diabetes can be produced by intravenous, intramuscular, subcutaneous, administration of different doses. In this study, adrenaline $8 \mathrm{mg} / \mathrm{kg}$ by intravenous route has been sued as the route is least toxic. The protocol of the study was approved by IAEC, Gayatri College of Pharmacy, Sambalpur, India, bearing Regd. No1339/ac/10/CPCSEA.

\section{Experimental design}

Method used by Mohan et al. (1978) was followed to study the affect of BMLE on the fasting plasma glucose (FPG) at different hour's intervals. Adrenaline was administered in the dose $0.8 \mathrm{mg} / \mathrm{kg}$ for induction of diabetics. In addition, high carbohydrate diet has been employed for experimental animal to maintain the good diabetic model. Adrenaline is responsible for hyperglycemia in an animal model, and high carbohydrate diet plays a synergistic role for maintaining diabetes $[8,9]$. The diabetic rabbits with FPG level 200-250 mg/dl were divided into different groups of six animals each in the following manner. The detail is present in Table 1.

\section{Determination of blood glucose levels}

Blood samples from the overnight fasted diabetic rabbits were collected. Then, the drug and the vehicles in their indicated doses were administered orally to the respective groups. The effect of BMLE on FPG was compared to that of their respective vehicle and glibenclamide, the standard antihyperglycemia drug at different time interval by photocolorimeter. The detail is present in respective table.

\section{Statistical analysis}

Blood glucose levels were expressed in $\mathrm{mg} / \mathrm{dl}$ as mean $\pm \mathrm{SEM}$. The data were statistically analyzed using ANOVA with multiple comparisons versus control group. The values of $\mathrm{p}<0.01$ were considered as significant [10].

\section{RESULT AND DISCUSSION}

Adrenaline-induced hyperglycemia has been described as a useful experimental model to study the activity of antidiabetic agents as adrenaline is responsible for elevated glucose label by producing glycogenolysis. The following table shows the result of the effect of three doses $(100,200$, and $400 \mathrm{mg} / \mathrm{kg}$ ) of the ethanolic extract of B. monosperma leaves.

BM leaf extract administered in doses of 100,200 , and $400 \mathrm{mg} / \mathrm{dl}$ to three different group of diabetic rabbits whose FPG was estimated just before (Ohr) and 2, 4 as well as $8 \mathrm{hrs}$ after the drug administration. In Table 2, the effect of vehicle on FPG has been noted. This table bears the report of the FPG of the diabetic rabbits $0 \mathrm{hr}$ (before) and 2, 4 and $8 \mathrm{hrs}$ intervals after administrations of different vehicles. Here, $\mathrm{p}<0.05$ after analysis by one-way ANOVA. There is no significant difference between the mean FPG of all groups. Hence, none of the vehicles have any significant action. In Table 3, the effect of different doses of BM leaf extract on adrenalineinduced diabetic animal has been mentioned. BM leaf extract at 100, 200 , and $400 \mathrm{mg} / \mathrm{kg}$ dose has been administered and glucose level has been monitored at $0 \mathrm{hr}$ (before) and $2 \mathrm{hrs}, 4 \mathrm{hrs}$ and $8 \mathrm{hrs}$ intervals after administration. One-way ANOVA analysis shows $\mathrm{p}<0.01$ which indicates statistical significance. At $4 \mathrm{hrs}$ reading and $8 \mathrm{hrs}$ reading there is a significant lowering of FPG. In 8 hrs reading the lowering of FPG is very prominent. Table 4 is a consolidated table showing the effect of BMLE at 3 dose level and glibenclamide $0.5 \mathrm{mg} / \mathrm{kg}$ on mean FPG of different groups of rabbits as compared to their respective vehicles at $0,2,4$, and $8 \mathrm{hrs}$ interval of drug administration. Statistical analysis by one-way ANOVA followed by paired t-test indicates the significant of result which has been mentioned in the respective table. The highly significant result has been indicated as triple star within the table. BMLE $100 \mathrm{mg}$ dose at 8 -hour interval achieve $203.5 \pm 3.92 .200 \mathrm{mg}$ dose at $8 \mathrm{hrs}$ interval achieve 191.33 \pm 5.14 .

Which is very effective and $400 \mathrm{mg}$ achieve $182.5 \pm 3.83$ which is very effective for reducing blood glucose level in the experimental animal.

The peak effect with each dose was observed at $8 \mathrm{hrs}$ with low dose the onset of antihyperglycemic action was delayed whereas with high dose an early response was observed $[11,12]$.

Table 1: Details of Drug, Vehicle and Routes of Administration

\begin{tabular}{llll}
\hline Drug/vehicle & Dose per kg body weight & Route of administration & Nature of use \\
\hline $5 \%$ Tween 80 & $2 \mathrm{ml}$ & Oral & Vehicle for SRLE \\
Glibenclamide & $0.5 \mathrm{mg}$ & Oral & Standard antihyperglycemic drug \\
SRLE & 100,200 and $400 \mathrm{mg}$ & Oral & Indigenous test drug \\
Adrenaline & $0.8 \mathrm{mg}$ & I.V & Diabetes inducing agent \\
\hline
\end{tabular}

Table 2: Effect of vehicles on fasting plasma glucose in adrenaline-induced diabetic rabbits (acute study)

\begin{tabular}{|c|c|c|c|c|c|c|c|c|c|c|c|c|}
\hline \multirow[t]{3}{*}{ S. No. } & \multicolumn{12}{|c|}{ FPG (mg/dl) } \\
\hline & \multicolumn{4}{|c|}{ Distilled water } & \multicolumn{4}{|c|}{$2 \%$ gum acacia } & \multicolumn{4}{|c|}{$5 \%$ Tween 80} \\
\hline & 0 hrs & 2 hrs & $4 \mathrm{hrs}$ & 8 hrs & 0 hrs & 2 hrs & 4 hrs & 8 hrs & 0 hrs & 2 hrs & 4 hrs & 8 hrs \\
\hline 1 & 239 & 239 & 231 & 224 & 236 & 232 & 228 & 219 & 245 & 241 & 243 & 239 \\
\hline 2 & 237 & 234 & 238 & 225 & 238 & 234 & 236 & 238 & 235 & 236 & 231 & 225 \\
\hline 3 & 232 & 227 & 223 & 232 & 231 & 224 & 223 & 225 & 232 & 229 & 233 & 224 \\
\hline 4 & 244 & 228 & 237 & 238 & 243 & 238 & 237 & 231 & 234 & 233 & 235 & 231 \\
\hline 6 & 226 & 233 & 228 & 226 & 225 & 228 & 227 & 223 & 227 & 229 & 224 & 233 \\
\hline Mean & 234.83 & 231.5 & 231.33 & 228.5 & 233.8 & 230.3 & 230.0 & 227.17 & 230.0 & 230.5 & 231.2 & 227.5 \\
\hline
\end{tabular}

One-way ANOVA p>0.05ns, ns: Not significant. This table bears the report of the FPG of the diabetic rabbits $0 \mathrm{hr}$ (before) and 2, 4 and $8 \mathrm{hrs}$ intervals after administrations of different vehicles. There is no significant difference between the mean FPG of all groups. Hence, none of the vehicles have any significant action on FPG levels of diabetic rabbits, and there is no significant difference among the effects of these three vehicles 

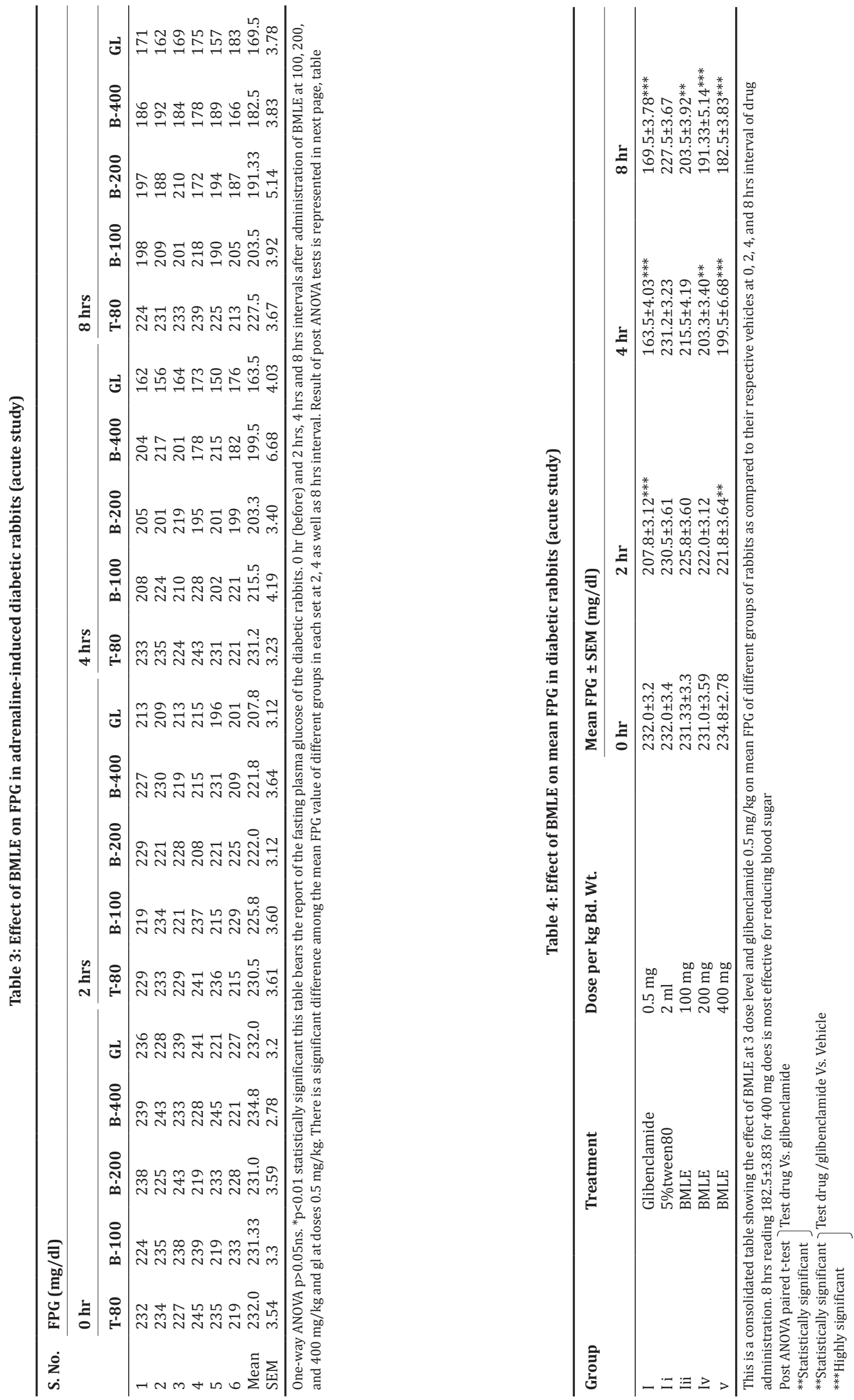


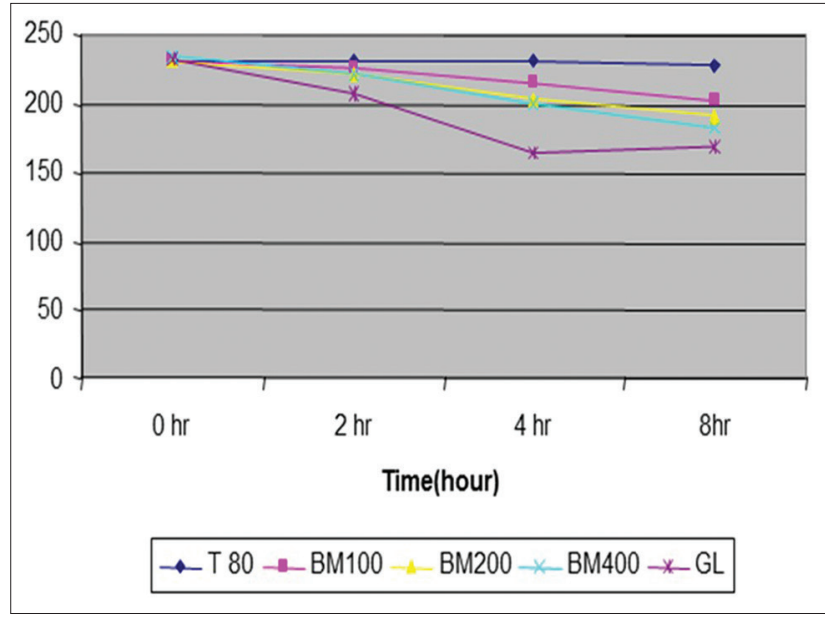

Graph 1: Effect of Bmle on Fpg in Diabetic Rabbit

\section{CONCLUSION}

The study indicates that the ethanolic extract of $B$. monosperma leaves possesses antidiabetic properties which suggest the presence of biologically active components. The extract might be promoting glucose uptake and metabolism or inhibiting hepatic gluconeogenesis. BM leaf extract administered in doses of 100,200 , and $400 \mathrm{mg} / \mathrm{dl}$ to three different group of diabetic rabbits whose FPG was estimated just before $(0 \mathrm{hr})$ and 2, 4 as well as $8 \mathrm{hrs}$ after the drug administration. The results of this study depicted in Table 2 and Graph 1 reveal that the drug exhibited a significant effect on FPG of diabetic rabbits. Post ANOVA analysis of the data by paired $t$-test reveals that BMLE with $100 \mathrm{mg} / \mathrm{kg}$ dose reduced mean FPG levels in diabetic rabbits significantly at $8 \mathrm{hrs}$; with $200 \mathrm{mg} / \mathrm{kg}$ at 4 and $8 \mathrm{hrs}$; and with $400 \mathrm{mg}$ at 2,4 as well as at 8 hrs intervals in comparison to its vehicle. The peak effect with each dose was observed at $8 \mathrm{hrs}$. With low dose, the onset of antihyperglycemic action was delayed whereas with high dose an early response was observed [13].

\section{REFERENCES}

1. Ganong WF. Review of Medical Physiology. $21^{\text {st }}$ ed. New York: McGraw-Hill Professional; 2003.

2. Garatini S, Paoleti R, Bizzi L, Gmssi E, Vertua A. Drugs Affecting Lipid Metabolism. Amsterdam: Elsvier; 1961. p. 1-44.

3. Kirtikar KR, Basu BD. Indian Medicinal Plants. Vol. 1. Allahabad, India: Lalit Mohan Basu, Prakashan; 1991. p. 785-9.

4. Rosenthaler L. The Chemical Investigation of Plant. $1^{\text {st }}$ ed. London: Bell and Sons; 1930

5. Suganya G, Kumar PS, Dheeba B, Sivakumar R. In vitro anti diabetic, antioxidant and anti-inflammatory activity of Clitoria ternatea. Int J Pharm Pharm Sci 2014;6(7):342-7.

6. Ali M. Textbook of pharmacognosy. Treaseand Evans Pharmacognosy. $13^{\text {th }}$ ed. London: Bailliere Tindall; 2002.

7. Agbafor KN, Nwachukwu N. Phytochemical analysis and antioxidant property of leaf extracts of Vitex doniana and Mucuna pruriens. Biochem Res Int 2011;2011:459839.

8. Kokate CK. Practical Pharmacognosy. $4^{\text {th }}$ ed. New Delhi, India: Vallabh Publications, Prakashan; 1994

9. Naik SR, Barbosa Filho JM, Dhuley JN, Deshmukh V. Probable mechanism of hypoglycemic activity of bassic acid, a natural product isolated from Bumelia sartorum. J Ethnopharmacol 1991;33(1-2):37-44

10. Mandlik RV, Desai SK, Naik SR, Sharma G, Kohli RK. Antidiabetic activity of a polyherbal formulation (DRF/AY/5001). Indian J Exp Biol 2008;46(8):599-606.

11. Evangeline RM, Murugan N, Kumar PP, Christhudas IV. In vitro studies on a glucosidase inhibition anti oxidant and free radical scavenging properties of Tecoma stans L. Int J Pharm Sci 2015;7(7):44-9.

12. Ghosh MN. Statistical methods. In: Fundamentals of Experimental Pharmacology. $3^{\text {rd }}$ ed. Kolkata: S.K. Ghosh and Others, Hilton and Company; 2005. p. 209-29.

13. Grover JK, Vats V, Rathi SS. Anti-hyperglycemic effect of Eugenia jambolana and Tinospora cordifolia in experimental diabetes and their effects on key metabolic enzymes involved in carbohydrate metabolism. J Ethnopharmacol 2000;73(3):461-70. 